\title{
25th Anniversary of Pathology Oncology Research
}

\section{Kopper ${ }^{1} \cdot$ J. Tímár ${ }^{2}$}

Received: 8 January 2020 / Accepted: 13 January 2020 / Published online: 22 February 2020

(C) Arányi Lajos Foundation 2020

The international journal, Pathology Oncology Research (PORE), established in 1995 by the founding Editors, László Kopper, Judit Nagy, Zsolt Orosz and József Tímár. The aim of launching PORE was to promote pathological and oncological publishing activity of scientists in Central and East Europe. Those were the years when the 200 year old conservative science, histopathology, began to transform into a „rocket science" discipline with the development of molecular pathology. These developments affected the every day routine of diagnostic pathology but fundamentally affected also the clinical practice as well. Major beneficiary of that transformation was medical oncology. As the Founding Editors were active participants of these changes the profile of the new Journal was unquestionable. The owner and founder of PORE is the Arányi Lajos Foundation for Modern Pathology. The Foundation is named after Lajos Arányi (1812-1887), the founding father of the first pathology department in Hungary back to 1844 at the Medical Faculty of Pazmany University, Budapest (est. 1769, today Semmelweis University). This was the 5th Department after Vienna, Edinburgh, Strasburg and Paris. Arányi was the author of the first Hungarian textbook of pathology (1864) and his research included edema, narcosis and suffocation. Arányi's idea of complementary private support for state-financed medical institutions was revitalized by

L. Kopper

kopper@korb1.sote.hu

J. Tímár

jtimar@gmail.com

1 Department of Pathology and Experimental Cancer Research, Budapest, Hungary

2 Department of Pathology, Semmelweis University, Budapest, Hungary the founders of Arányi Lajos Foundation who became the founders of the new Journal as well.

The lunch of the new journal happened in 1995 with one issue [1] and the first complete publishing year was 1996 with 4 issues containing 24 original articles, 7 reviews and 7 case reports. Starting as a PubMed-referred Journal, obtained an international reputation backed by the publisher Saunders (Elsevier) for years. PORE received its first impact factor in 2004 when was run independently by the Foundation. From 2007 the publisher of PORE is Springer (later on the SpringerNature group) the help of which PORE outgrown as a really international translational science Journal still run by its founding editors, László Kopper and József Tímár and an International Editorial Board but still with a significant presence of the Semmelweis Faculties. Till today PORE published appr. 2300 articles for those appr. 2100 citations can be found in the biomedical literature and the yearly usage of the Journal's articles passed $10^{5}$ downloads. Equally important is that the latest Thompson-Reuters impact factor of PORE is now 2.44 ranked 56th among 202 Pathology titles and 183rd among 368 Oncology titles according to Scimago SJR. As compared to the first volume in 1995-96, in the 2019/volume 25, PORE published 4 reviews, 219 original articles, 2 Short Communications and 7 Letters. The number of yearly submissions passed 1000 with an acceptance rate of $25 \%$. PORE reached its adult age but still has a growing potential if can accomodate to the changing scientific publishing environment.

\section{Reference}

1. Kopper L (1995) Prologue. Pathol Oncol Res 1:6

Publisher's Note Springer Nature remains neutral with regard to jurisdictional claims in published maps and institutional affiliations. 